\title{
El acto administrativo complejo en la esfera local
}

Sumario: 1. Introducción.-2. Concepto de acto administrativo complejo.-8. Examen de algunos supuestos que han sido considerados por la doctrina como actos complejos: a) la autorización y aprobación de los acuerdos de los entes locales; $b$ ) los acuerdos de unión de términos municipales; c) los acuerdos de constitución de una Mancomunidad.-4. Diferencia entre el acto complejo y figuras afines: $a$ ) el acto colectivo; $b$ ) el acto colegial.

1. Entre las muchas clasificaciones propuestas por la doctrisa en su intento de abarcar y reducir a sistema la intrincada maraña de los actos administrativos se encuentra aquella que, basándose en el número de personas u órganos que intervienen en la formación de su contenido, distingue entre el acto administrativo simple y el complejo. Ia categoría del acto administrativo complejo tiene su origen, como tantas otras de nuestra ciencia, en la doctrina alemana, de donde, especialmente a través de la formulación de G. Jellinek, en su Sysiem der Subjekriven offenslichen Rechte (1), pasó a la doctrina italiana (2), que la consa-

(1) Vide la traducción italiana, Sistema dei Diritti pubblici subbiettivi, Roma, 1912, en especial pág. 20. y ss.

Se puede decir que la primera enunciación clara del acto complejo fué ofrecida por Grenke, a propósito del acto ảe fundación de las corporaciones, que es considerado por este autor no como un contrato, sino como un acto complejo unilateral (Genosseirschafthéorie usid die deisische Rechisprechung, Berlin, 18s7, capitulo I, pág. 132 y ss.). El concepro de acto comp?ejo es después pcco a poco perfeccionado y aclarado por Karlowa, Binding, Jerriner, Kuntze y Triepiz.

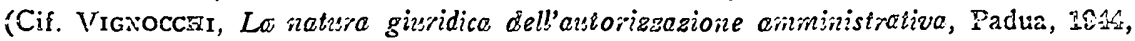
วágुs. 4 y j̃.

(8) Viac Brond: L'atto complesso nel Diritio pisbblico, en Stidi it onore

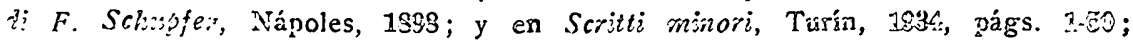


gró en la forma normalmente seguidas por la doctrina patria (3). Los autores españoles, sin embargo, no la han hecho objeto hasta el momento, de un estudio especial (4). Estudio que nos parece conveniente, e incluso necesario, pues, como Forti ha puesto de manifiesto, la creación y el reconocimiento de la citada categoría "ha hecho más mal que bien, siendo superiores, sobre todo en la práctica, las desviaciones y los errores que de ella han derivado a las ventajas obtenidas" (5). Ello obedece a la' confusión operada al intentar incluir dentro de su ámbito todos los supuestos de cooperación de distintos sujetos u órganos en la formación de un acto administrativo, o, hablando con más propiedad, de un acto jurídico, ya que el instituto ha sido admitido tanto en el Derecho público como en el Derecho privado (6). Parece como si el término complejo se interpretase en el sentido de "complicado" y hubiese servido por ello para encuadrar a todos aquellos supuestos de difícil calificación.

No es necesario advertir que el primer problema a plantearnos será el del concepto mismo del acto complejo. Al abordarlo seguiremos la trayectoria histórica, en la que ha sido objeto de lina progresiva depuración. Una vez alcanzado nuestro objetivo habrá que considerar la existencia de actos complejos en

Donatr: Atto complesso, autorizacione, approvazione, en «Archivo giuridicon, 1003, págs. 1-105; BorSI; L'esecutorietà degli atti amministrativi, en aStudi Senesid, Turín, 1901 y L'atto amministrativo complesso, también en eStudi Senesid, Turín, 1903 ; BrACCI: Dell'atto complesso in Diritto amministrativo, Siena,.1927; GASPARRI: Studi sugli atti giuridici complessi, Pisa, 1939; Caserta: Accordo e Contratto, aAnnali dellạ Facoltà di Giurisprudenza della Università di Bari», 1.343, págs. 213-247.

(3) Cfr. Gascón y Makf : Tratado de Derecho Administrativo, Madrid, 1950,

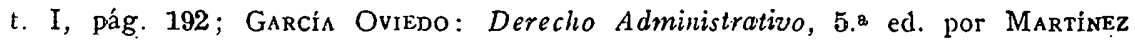
Useros, Madrid, 1950, t. I, pág. 170 y ss.; Royo-Villaxova: Elementos de Derecho Administrativo, Valladolid, 1948, t. I, pág. 105.

(4) Escasas indicaciones se contienen en FERníndez de Velasco: Relaciones juridicas bilaterales, aRevista General de Legislación y Jurisprudencian, mayo, 1924.

(5) Lezioni di Diritto admministrativo, Farte general II, Nápoles, 1950, pág. 92.

(6) Cfr. BetTr: Teorio Geincral del Negocio Jurídico, trad. esp. por Martin PÉrez de la italiana de 1953s, Madrid, pág. 222 y ss.; Von Trur: Tratado de las Obligaciones, I, Madrid, 1934, pág. 102; Branca: Istituszioni di Diritto privato, Bolonia, 1956, págs. 62 y 63. 
nuestro ordenamiento jurídico, :o que haremos, como indica el epígrafe que eincabeza estars páginas, con especial referencia a la esfera local.

2. Al ocuparse de los actos del Estado que crean derechos escribia G. Jellinek: "La voluntad die manifestaciones concordes prevalece en el Derecho privado, pero se encuentra también en el Derecho público, especialmente en la forma de $V e$ reinbarung. Vereinbarung es la creación de una voluntad unitaria, jurídicamente relevante, mediante distintos actos de voluntad individual, independientemente de que emanen de los particulares como tales o de órganós de la colectividad. Contrato, en cambio, es el acuerdo de varias personas acerca de la ejecución o la recepción de prestaciones. Vereinbarung es la unificación de distintas voluntades al objeto de conseguir la satisfacción de intereses comunes; contrato es una unión de voluntades para satisfacer intereses contrapuestos e incluso no congruentes entre sí. La Vereinbarung se presenta siempre que varias. voluntades consideradas separadamente carecen de la potestad jurídica de producir un determinado acto de voluntad jurídicamente relevante. De la voluntad de varios individuos no es posible que resulte una voluntad físicamente única, pero una voluntad jurídicamente única puede perfectamente ser creada por el ordenamiento jurídico. Todas las aprobaciones, los actos en colaboración y, en general, todos los actos que resultan de un acuerdo de varias personas, tan frecuentes en la formación de la voluntad del Estado, no son sino Vereinbarung" (7).

La distinción de Jellinek es recogida por Brondi en 1898 (8) y desarrollada por Borsi en sendos estudios aparecidos en 1901 (9) y 1903 (10). Según el antiguo profesor de la Universidad de Bolonia, acto administrativo simple es aquel en que la voluntad de un ente público se determina y se concreta mediante la manifestación de voluntad de una sola persona física, mientras que en

(7) Sistema cit., pág. $25 \overline{0}$.

(8) L'atto complesso cit.

(9) L'esecutorietd cit.

(10) L'atto amministrativo cit. 
el acto administrativo complejo, la voluntad única del ente o de varios entes cooperantes se determina mediante el concurso en orden a un mismo objeto de las manifestaciones de voluntad de varias personas físicas o morales que tienen un interés idéntico bajo el aspecto jurídico. El acto compiejo, continúa el mismo autor, puede ser igual o desigual; si la participación de cada uno de los quereres concurrentes corresponde en medida e importancia (jurídicamente valorada) a la.participación del-otro, y desigual en el caso contrario. Tanto los actos iguales como los desiguales pueden representar la expresión del querer o de un ente jurídicamente único, o de lla unión de hecho de entes jurídicamente distintos. En el primer caso, los actos iguales se llaman actos colegiales; en el segundo, acuerdos. Los actos desiguales en el primer caso resultan del concurso de las manifestaciones volitivas de autoridades jerárquicamente ordenadas; en el segundo, del concurso de las voluntades de entes diversos, una de las cuales representa la parte principal y la otra o las otras la parte accesoria del acto. Complemento de esta postura era la inadmisibilidad de los contratos de Derecho público de la Administración. No podían darse entre la Administración y los particulares, porque la naturaleza jurídica de ambos' es demasiado diferente. Pero tampoco entre entes públicos, porque en la práctica no se da el caso de que se crucen las voluntades de dos entes públicos para constituir, modificar o extinguir un vínculo que tenga naturaleza de Derecho público (11).

La tesis de Borsi alcanzó gran predicamento en la época de su publicación $y$ ha sido durante mucho tiempo la dominante, con más o menos variantes, en la doctrina italiana. Pero, si bien se mira, su interés es bien escaso. Como ha subrayado Forti, Ia utilidad de los problemas sistemáticos radica en que la definición sistemática de un fenómeno jurídico implica la clasificación del mismo y la posibilidad de aplicar al fenómeno así clasificado las normas que el Derecho ha establecido para aquella

(11) Un resumen de la tesis de Borsi puede verse en Le funzioni del Comune italiano, en el Primo Trattato de Orlando, II, p. 2.\$, págs. 22 y $9 s$. 
categoría de fenómenos (12). Esta utilidad no aparece en el caso presente, ya que, como apunta De Valles, se clasifica en la misma categoría una serie de actos con la única nota común de que no son (o no se consideran) un contrato (13).

Aquí es justamente donde radica el error fundamental del planteamiento efectuado. Como Bracci afirma, el acto complejo no debe ser estudiado en relación con el contrato, sino cón el proceso de formación de la voluntad, ya que un acto complejo puede ser un elemento de un contrato, y, además, mientras que en el primero la voluntad es única, ell el segundo existen dos o más voluntades (-14). Por esta razón, creemos que la única forma de enfocar adecuadamente la cuestión que estamos tratando es la iniciada por Donati, que considera el acto juridico como un posterius con relación al poder de que procede. Todo poder, señala este autor, resulta de dos elementos o poderes elementales: el poder de pertenencia exclusiva de una determinada esfera de actividad (poder mudo) y el poder de ejercicio de la actividad reconocida dentro de los límites de aquella esfera (facultad de ejercicio del poder). Cuando el ejercicio del poder está atribuído a distintos sujetos u órganos, nos encontramos, en la opinión de Donati, ante uná voluntad compleja, que atribuirá al acto en que se manifieste el carácter de acto complejo. Para ello, es necesario el concurso de los siguientes requisitos: $1 .^{\circ}$, que las declaraciones de voluntad de los distintos sujetos $u$ órganos tengan idéntico contenido; $2 .^{\circ}$, que se dirijan a la producción del mismo efecto, y $3 .^{\circ}$, que dicho efecto sea querido para la satisfacción no de intereses iguales o comunes, sino de un único o solo interés (15). De esta suerte, se restringe considerabiemente el número de actos complejos al eliminar a los colegiales y a los de complejidad desigual. A los primeros, porque en ellos no concurren distintos sujetos u ór-

(12) Lezionz cit., vol. II, pág. 87.

(13) Teoría giuridica della organizaazione dcllo Stato, II, Paóuz, 193e, pác̆. 23.

(14) Dell'atto coinplesso cit., pág. 17 y ss. En igual sentidio, Vignocciz:: Ls natiera giusridica cit., pág. 6.

(15) L'arbo complesso cî́., gág. 5 y ss. 
ganos, ya que las personas que integran un órgano coiegial no tienen aquel carácter. En cuanto a los segundos, porque las declaraciones de voluntad que, según Borsi, los integrarían, no se dirigen a la producción de un mismo efecto para la satisfacción de un único interés. Se mantiene, sin embargo, la distinción entre los actos de complejidad interna y los de complejidad externa, denominados acuerdos. Esta postura es la mantenida entre nosotros por Royo Villanova (16).

Creemos, sin embargo, que debe restringirse aún más el ámbito de aplicación del instituto jurídico que venimos examinando. Si se piensa en el tercero de los requisitos que estimamos deben concurrir para que pueda hablarse de acto complejo, se comprenderá la dificultad de que éste pueda estar integrado por la voluntad de distintos sujetos. Cada uno de ellos, en efecto, tenderá a la defensa de sus propios intereses, que, a lo sumo, serán comunes a los mismos de los del otro o los otros sujetos. Pero nunca podrá hablarse de "un único o solo interés". Concretándonos a la esfera local, no resulta difícil advertir que cada Municipio tiene intereses propios, para cuya gestión se le atribuyen por el Estado aquella serie de facultades o funciones qué, entendiendo el término en un sentido absoluto, integran su competencia (17). Cuando dos Mumicipios acuerdan, por ejemplo, solicitar que se decrete su fusión, supuesto normalmente considerado, como más adelante veremos, como acto complejo en su modalidad de acuerdo, no miran a un único interés, sino a la defensa de aquellos cuya gestión se les ha encomendado. No deja de ser significativo a' este respecto el hecho de que el mismo Royo Villanova hable en tal caso de contrato y no de acto de complejidad externa $(18,19)$.

(16) Elementos cit., I, pág. 105 y Problemas del Régimcn Juridico Municipal, Madrid, 1944, pág. 22.

(17) Cfr. Royo-Villavova: Problemas cit,. págs. 24 y 25.

(18) Los términos municipales y sus alteraciones, Madrid, 1947, pág. 41.

(19) Nuestra postura coincide con la seguida por FortI: Lezioni cit., pág. 98 y ss. Interesa consignar que el mismo autor admitió en otra época la existencia de actos de complejidad externa ( $I$ controlli sull'Amministraziones Comunale, en el vol. II, p. 2.3 del Primo Trattato de Orlando cit., pág. 740). 
Dos objeciones pudieran oponerse a nuestra tesis: el carácter estatal que tienen todas las actividades de los entes locales y, en general, de todas ias personas juridicas de carácter público, y la posibilidad de que la gestión de las actividades conducentes a la satisfacción de un solo interés esté encomendada simultáneamente a la Provincia y al Municipio.

Como es sabido, los intereses gestionados por los entes locales son al mismo tiempo intereses estatales. Pero desde el momento en que el Estado reconoce la competencia de dichos entes accrca de ellos, el aspecto predominante de los mismos es el municipal o provincial. Cuando el Estado interviene no to hace para gestionar dichos intereses, sino para velar, mediante el sistema de controles de tutela, por la adecuación de la actividad de los entes locales al interés general.

En las Jornadas Municipalistas en las Islas Canarias, ceiebradas a fines del pasado invierno, pronunció Garcia de Enterría una conferencia, cuyo texto acaba de pubilicarse, sobre La Provincia en el Régimen local español. En dicha conferencia se llama la atención sobre un fenómeno que hasta ahora había pasado desapercibido a la doctrina patria : la "provincialización" de nuestro régimen local. "Es fácil demostrar-advierte el citado autor-que la Provincia ha absorbido funciones del Municipio en la nueva estructura. Esta succión de la autonomía real del Municipio para fortalecer su propia autonomía, la ha cumplido la Provincia en dos órdenes de materias: 1) por una parte, en cuanto al aspecto financiero; 2) por otra, en cuanto a la esfera de gestión de servicios" (20). Sin detenernos a considerar la importancia, por otra parte manifiesta, de esta nueva aportación del catedrático de la Universidad de Valladolid, lo que interesa estudiar es la posibilidad de una confusión de los intereses provinciales y municipales. De admitirla, tendríamos que rectificar la tesis anteriormente sentada. Estimamos que tal confusión no se ha producido. Es cierto que la Ley de Régimen local, siguiendo en este punto las orientaciones del Dere-

(20) Ias Palmas de Gran Canaria, 1957, págs. 14 y 15. Existe separata. 
cho comparado, y muy especialmente 'as de Inglaterra (21), ha robustecido extraordinariamente la competencia de la mayor de nuestras circunscripciones territoriales, la Provincia, a costa de las que correspondían a las inferiores. Pero basta una simple lectura de los artículos 255 y siguientes de aquélla para percatarse de que la esfera de actuación de nuestros entes locales continúa estando claramente delimitada.

Resumiendo, por tanto, en nuestra opinión, para que exista acto complejo es necesaria la concurrencia de los siguientes requisitos: 1) varias declaraciones de voluntad de distintos órganos (no de distintos sujetos) de un ente público; 2) que dichas declaraciones se dirijan a la producción del mismo efecto, y 3) que este efecto sea querido para la satisfacción de un único y solo interés.

De esta suerte, se reduce extraordinariamente el ámbito de aplicación de esta especie de actos. Pero al mismo tiempo, gana en interés y utilidad la categoría que acabamos de precisar. Cuando una de las voluntades que han de concurrir para la formación del acto complejo está viciada, no habrá llegado a constituirse la voluntad compleja exigida por la Ley, y al no existir una declaración de voluntad debidamente formada, el acto que se emane estará viciado de invalidez, en su grado de nulidad (22). Nos encontrariamos, en efecto, ante un supuesto de incompetencia funcional, ya que los dos órganos tienen competencia sobre la materia de que se trate (el poder nudo de que hablábamos más arriba), pero para ejercerla (facuitad de ejercicio del poder), han de actuar conjuntamente. Conviene, a este respecto, recordar que la competencia, según palabras de D’Ales-

(21) Vide sobre el particular nuestro trabajo, que aparecerá próximamente, Los movimientos centralizadores en Inglaterra y bibliografia alli citada.

(22) aEl acto complejo, escribe ForT, por defunición no existe, si no han intervenido todas las voluntades necesarias para su formacións (Lezioni cit., pág. 95).

No es esta ocasión de penetrar en la polémica entre las tesis de biparticipación y de la triparticipación en la teoría de la invalidez del acto administrativo. Consúltese Garrido Falla: Régimen de impugnación de los actos administrativos, Madrid, 1956, cap. V. 
sio (23), es "la medida de la potestad que pertenece a cada órgano".

Interesa ahora averiguar los supuestos de actos complejos existentes en la esfera local. Hablando de los actos complejos en general, afirma Garrido Falla que "si intentáramos buscar en nuestro Derecho ejemplos concretos de actos complejos, nos encontrariamos con que se trata de una figura jurídica nada corriente" (24). En término parecidos se expresa Royo Villanova al señalar que "la verdad es que el número de acuerdos municipales complejos es reducidisimon (2כ). Nosotros nos atrevemos, modestamente, a ir más lejos. Creemos que, con arreglo al Derecho vigente, no existe en la esfera local ningún acto administrativo al que deba acompañar el calificativo de complejo. Ello nos fuerza a examinar algunos supuestos que han sido considerados, en ocasiones, como tales: estos supuestos se clan en materia de controles de tutela, de alteración de términos municipales y de constitución de asociaciones entre entes locales.

a) Como es sabido, una de las características del Estado de nuestros días consiste en la creación o el reconocimiento dentro de su ámbito de una serie de personas jurídicas de carácter público a las que encomienda el cumplimiento de alguros de los fines que asume. Sin embargo, los intereses cuya gestión se encomienda continúan siendo estatales, por lo que el Estado no puede desentenderse de la actuación de los entes públicos menores. A tal fin, la Ley le concede una serie de poderes limitados sobre las autoridades de dichos entes y sobre sus actos. Esta serie de poderes constituyen, según la definición de Maspetiol y Laroque, la tutela administrativa (26).

La forma más frecuente de controlar los actos emanados por los entes descentralizados, y concretamente por el Municipic

(23) Istitisaioni di Diritto anministiativo, t. I, Turin, 1932, pág. 230.

(2A) Régimen de impugnación cit., pág. 172. Considera Garrido Falla comr: acios complejos las órdenes ministeriales conjuntas (loc. cit.).

(9) Problemas cit., fág. 22.

(28) Lo tarielle adininistrative, París, 1030, pág. 10. 
y ia Provincia, que son ios que ahora nos interesan de un modo espec:ar, consiste en exigir que dichos actos sean autorizados o aprobacios por la Administración central.

El concepto de autorización y aprobación no es, ni mucho menos, preciso en nuestro ordenamiento jurídico. Por lo que a la Ley de Régimen local se refiere, sin embargo, no ofrece serias dificultades (27). Es cierto que, en ocasiones, la terminología es confusa. Así, en el artículo 189, 2, después de haber exigido la autorización para poder realizar determinados actos, habla de aprobación, y lo contrario ocurre en el artículo 688 . Del conjunto del articulado se deduce, no obstante, que la autorización tiene carácter previo a la emanación del acto, removiéndose con ella los límites que se oponen al ejercicio de un poder juridieo o un derecho preexistente (28), según la terminología consagrada por la doctrina italiana (29); mientras que el acto de aprobación se emana con posterioridad al acto aprobado, completando así, como apunta Sayagués, su eficacia jurídica (30).

Como ya hemos tenido ocasión de advertir, algunos autores, como G. Jellinek (31), Borsi (32) y Presutti (33), han estimado que la autorización y la aprobación vendrían a integrar la voluntad del énte controlado, con llo que la autorización y el acto autorizado o el acto aprobatorio y el aprobado constituirían un acto complejo. Se nos plantea, por tanto, el problema de determinar la exactitud de tales aserciones, y, caso de que el examen dé un resultado negativo, el de desvelar la verda-

(27) Vide para la autorización los artículos 166, 2 y $3 ; 189,1$ y $2 ; 190,181$, 361 y 659, 2 y 3 . Para la aprobación, $22,24,25,34,110,132,169,189,192,194$, $255,257,361,303,685,688,689,700,701$ y 726 .

(28) Para la diferencia entre poder juiridico y derecho subjetivo, vide SAnt Romano: Poteri, Pọtesta, en Frạnmenti di usn dizionario giuridico, Milán, 1953, págs. 171-203, en particular, 173 y 174.

(29) Vide, por todos, RanelletTI, Concetto e natura delle astorizzazioni e concessioni amministrative, en aGiurisprudenza italianas, 1894.

(30) Tratado de Derecho administratizo, I, Montevideo, 1953, pág. 417.

(31) Sistema cit., pág. 255.

(32) L'atto amministrativo cit., pág. 3 y ss.

(33) Istitusioni di Diritto amministrativo, II, Mesina, 1231, pág. 3a4 y ss. 
dera naturaleza de los actos consignados. La cuestión es importante, ya que las consecuencias jurídicas de la falta de éstos serán distintas según la conclusión $a$ que se llegue.

$\mathrm{Si}$ se recuerdan los requisitos que estimábamos deben concurrir para que se dé un acto complejo, se comprenderá la imposibilidad de asignar tal naturaleza a los actos a que acabamos de referirnos. Son distintos, en efecto, el contenido, los efectos que producen y los intereses que con ellos se pretenden tutelar. Con esto, por lo demás, no hacemos sino sumarnos a la doctrina dominante (34), de la que Clavero (35), Garrido Falla (36) y González Pérez (37) pueden considerarse como los más modernos representantes en nuestra Patria. Una prueba de esta tesis puede encontrarse en la nueva Ley de la Jurisdicción contencioso-administrativa, de 27 de diciembre de 1956, cuyo artículo 29, tras establecer en su apartado primero que se considerará como parte demandada la A.dministración de que proviniere el acto o disposición a que se refiere el recurso, especifica en el apartado segundo que cuando una Corporación o Institución dictaren algún acto o disposición, pero éstos no fueren firmes sin previa autorización, aprobación o conocimiento de oficio o a instancia de parte, de la Administración estatal o de otra entidad administrativa, se entenderá por Administración demandada: a) la Corporación o Institución que dictare el acto o disposición fiscalizados, si el resultado de la fiscalización fuere aprobatorio del mismo, y b) la que ejerza la fiscalización, si mediante ella no se aprobare el acto o disposición (38).

(34) Vide, aparte los tratados generales, Doratr: Atto complesso cit., pág. 3 y ss.; Form : I controlli cit., págs. 762 y ss. y 776 y ss.; Celentano: I controlli sulle Amministrazioni degli enti territoriali locali secondo la vigente lègislazione. Turín, 1936, pág. 22 y ss.; Maspetiol y Laroque: La tutelle cit., 109 y ss.; Vignochi: La natura cit., pág. 4 y ss.

(35) Municipalización y provincialización de Servicios en la Ley de Régimen local, Madrid, 1952, pág. 112.

(36) Régimen de impugnación cit., pág. 174.

(37) Derecho procesal administrativo, II, Madrid, 1957, pág 239.

(38) Debe entenderse que el citado artículo modifica el régimen antericr en 
Dado que el acto controlante y el controlado no integran un acto complejo, deberemos seguir indagando acerca de ia naturaleza juridica de la autorización y la aprobación. Algunos autores, como Maspetiol y Laroque (39), y recientemente González Pérez (40), les dan un tratamiento unitario, al atribuirles el carácter de condición en sentido técnico. De ser exacta esta tesis, en el supuesto de que el acto de una entidad local no fuese autorizado o aprobado por la Administración central, sería válido, pero ineficaz. Estamos de acuerdo con 'estos autores en cuanto a la aprobación se refiere. No así en lo que a la autorización respecta.

Como es sabido, la doctrina no se ha puesto aún de acuerdo acerca de la admisibilidad y extensión de la categoría de lá condicio iuris. Aunque no falta quien, como Barbero, niegue la sustancial afinidad de funcionamiento entre aquélla y la condicio facti (41), puede afirmarse que en la actualidad los autores se inclinan hacia una solución positiva, manteniendo unos que debe considerársele como una condición impropio (42), y otros que la condicio facti y la condicio iuris no son sino especies de un genus común, lo que explicaría las analogías y diferencias existentes entre ambas (43). Cualquiera que sea la postura que

cuanto se oponga a lo que en él se dispone; asi, por ejemplo, articulos 687 y 726 de la Ley de Régimen local. Cfr. en este sentido. Gonźrez Prerez: Las Entidades locales en la Ley de la Jurisdicción contencioso administrativa, conferencia pronunciada en las Jornadas Municipalistas cit., pág. 10. No estamos de acuerdo con el iltistre tratadista cuando afrma que aen el régimen anterior siempre era parte demandada el Estadon. Estimamos, por el contrario, que, salvo en casos aislados, como los expuestos, el recurso contra los actos sometidos a la autorización o aprobación estatal, deberia interponerse contra el acto controlado, siendo parte demandada, por tanto, el ente que lo emanaba. Sic, Garrido Falla: Régimen de impugnación cit., pág. 174.

(39) La tutelle cit., pág. 110.

(40) Derecho procesal, cit., II, pág. 238.

(41) Contributo alla teoria della condizione, 1937, pág. 67 y ss., cit., por Bertı: La teoria cit., pág. 390 , en nota.

(42) Así Braica: Istituzioni cit., pág. 87.

(43) En este sentido, escribe Vignocur, ael instituto de la condición voluntaria, en lugar de representar con carácter exclusivo toda la categoría de la coadición, no es más que una parte, un sector, bien que muy amplio e importante, de la misma». (La natura, cit., pág. 103). 
en este segundo punto se adopte, en lo que existe unanimidad es al exigir que la condicio iruris se verifique después del acto condicionado, ya que, en caso contrario, sería muy difícil encontrar alguna analogía entre aquélla y la condicio facti, que justificara su asimilación (44). Ahora bien, la doctrina enseña, y, lo que es más importante, de nuestro Derecho positivo se desprende, como ya hemos puesto de manifiesto, el carácter previo de la autorización respecto del acto autorizado. De donde deriva la necesidad de oponerse a la calificación apuntada. A menos que se haga de la condicio iuris una categoría inservible $y$, por tanto, sin razón de existir. A mayor abundamiento, conviene recordar que, si no todos, la mayoría de los autores exigen igualmente que la condicio iuris encuadre únicamente aquellos actos o hechos que sean presupuestos de eficacia del futuro negocio, y no los que afecten a su validez. Circunstancia ésta que no se da en el caso de la autorización. Es imposible, en efecto, que la autorización afecte la eficacia de un acto concreto cuando necesariamente ha de preceder a su formulación. Entendemos, por ello, que la autorización, considerada en relación con el acto autorizado, constiquye un presupuesto de validez del mismo; mientras que si se le considera independientemente, es un acto a se staete, cuya función consiste en remover los límites que se oponen al ejercicio de un derecho o de un deber, y cuyos efectos se producen independientemente de que se emane o no el acto autorizado (45).

Nos queda ahora por averiguar en qué medida estará afectado de invalidez el acto que se emane sin que medie la previa autorización, es decir, si en grado de nulidad o de anulabilidad. Siguiendo la doctrina predominante (46) y las orientaciones de nuestra Jurisprudencia (47), nos inclinamos por la

(44) Vide, entre ctros, Branca:Istitzizioni, cit., pág. 87 y BETTI: Teoría, cit., pág. 389.

(45) Cfr. ForTI : I controlli, cit., págs. 764 y 765.

(48) Cfr. Vignocer: La natura, cit., pág. 131 y ss., y bibliografía alli cirada. Vide, en España, Garrido Falla: Régimen, cit., pág. 199 y ss.

(47) Especialmente interesante es la Sentencia de 21 de enero de 1936, en la you nuestro Tribunal Supremo declaró que en la esfera administrativa ha de ser 
segunda solución: ni la ley establece la nulidad del acto de una entidad local emanado sin la correspondiente autorización, ni los intereses en juego aconsejan adoptar tan drástica medida (48).

Las objeciones formuladas a la admisibilidad de la teoría que ve en la autorización y la aprobación una condicio iuris, desaparecen al referirse a la segunda, por lo que hemos de atribuirle esta naturaleza, con la consecuencia de que durante el estado de pendencia el acto de la entidad local será válido, pero ineficaz (49).

b) El segundo tipo de actos que debemos examinar, por haber sido considerados en ocasiones como actos complejos, se da, como anunciábamos, en materia de alteración de términos municipales. Según el artículo 12 de la vigente Ley de Régimen local, en su texto refundido de 24 de junio de 1955, los términos municipales podrán ser alterados: $1 .^{\circ}$, por incorporación de uno o más Municipios a otros limítrofes; $2 .^{\circ}$, por fusión de dos o más Municipios limítrofes; $3 .^{\circ}$, por segregación de parte de uno o de varios Municipios para constituir otro independiente; $4 .^{\circ}$, por segregación de parte de un Municipio para agregarla a otro limítrofe. El título de la alteración es siempre un acto del Gobierno, según se desprende del artículo 20 (50). Pero en el de unión de varios Municipios o de parte de uno de elloś a otro, es necesario distinguir entre la unión (incorporación, fusión. o segregación) voluntaria y la forzosa. En el primer caso, si el acto del Gobierno no ha sido provocado por la voluntad de los Municipios, debe conside-

aplicada con mucha parsimonia y moderación la-teoría jurídica de las nulidades (cit. por. Garrido Falla, op. cit., pág. 210).

(48) Recientemente, la Sala 4.a de nuestro Tribunal Supremo, en Sentencia de 4 de junio de 1957, ha declarado la anulidad radical» de un acuerdo municipal, epor la total inobservancia de los preceptos que regulan la actividad municipal en orden a las deudas y gastos de su erarion.

(49) En este sentido, Celentano: I controlli cit., pág. 25.

(अ) La vigente Ley de Régimen local es la menos autonomista de todas las leyes orgánicas que en la historia del Derecho español han regulado la alteración de los términos municipales (Cfr. S. Royo Villanova: Los términos municipales cit., págs. $27-30$ y 65 y ss.). 
rarse ilegítimo, aunque, en todo caso, se trate de un acto unilateral independiente de los que le preceden. Es necesario, por tanto, indagar la naturaleza del acuerdo de los Municipios en sí mismo considerado.

En el pasado, la doctrina era unánime al afirmar que tales acuerdos tenían carácter contractual (51). Pero cuando junto, o mejor, en oposición a la figura del contrato comenzó a adquirir relieve la del acto complejo, fué igualmente unánime entre los autores (52) la opinión de que los actos que examinamos constituían una de las manifestaciones más características de la nueva categoria. En defensa de esta tesis se argumentaba afirmando que se trata de actos cuyo contenidó se dirige a la unión y, por tanto, a la extinción del sujeto de que emanan; o que el efecto principal de los contratos era el de producir entre las partes un vínculo o relación jurídica, que faltaría en el śupuesto de Municipios que se unen, no sólo porque la unión ocasiona, como se ha dicho, la extinción de su personalidad, sino también porque todos los efectos de la unión derivan exclusivamente del acto estatal. Igualmente se advierte que si formalmente el acuerdo de los Municipios puede considerarse distinto de su solicitud de unión, en realidad, el acuerdo y la solicitud constituyen un solo acto volitivo, por lo que, si se atribuye carácter contractual al primero, debería hacerse igual con la segunda, lo que resulta manifiestamente absurdo (53).

Parece, sin embargo, que tales observaciones, como ha puesto de manifiesto Santi Romano (54), no son aceptables. Parten, en efecto, de un presupuesto injustificado: el de estimar

(51) De Gronnnis Gianquinto: Corso di Diritti pubblico, III, parte 1.8, Florencia, 1881, pág. 388; Porrint: Della sucessione dei Comuni, Archivo Giuridicon, IV, pág. 336 y ss. Citados por Santi Romano, Il Comune, Primo Trattato, II, parte 1.8, pág. 729.

(52) Asi, Brondr: L'atto complesso, cit., pág. 595 y ss.; Borsi: L'atto amministrativo, cit., pág. 38 y ss. y Jelliner: Sistema, cit., pág. 226.

(53) Cfr. Borsi, op. cit., pág. 39 y ss.

(54) Il Comune cit., pág. 730 y ss. Donde se desarrollan los argumentos que exponemos a continuación. 
que el acuerdo tiene como objeto inmediato la unión de los Municipios. Pero tal unión no es más que su última finalidad. El objeto inmediato es el de comprometerse a solicitar la emanación del acto estatal. Consideradas así las cosas, pierde valor la objeción de que el acuerdo de que nos ocupamos no puede constituir un contrato, por no tener tal naturaleza la solicitud que de él deriva. El uno y là otra no son elementos de un mismo acto volitivo, sino dos actos distintos, siendo la segunda consecuencia del primero, al representar el cumplimiento de la obligación que con él se asume. Desde este plano pierde igualmente su valor la objeción que en principio se habría considerado más grave: que el vínculo contractual no puede subsisitir entre Municipios que al unirse pierden su personalidad. Es cierto que cuando la unión se produce, dicho vínculo no subsiste, pero ha subsistido y ha producido todos sus efectos: los Municipios, al solicitar su fusión, han cumplido ya con las obligaciones contractuales que para ellos derivan del acuerdo, cuya relevancia juridica se manifiesta desde el momento en que se estipula hasta aquel en que se dirige al Gobierno tal solicitud. La doctrina que se combate sería exacta si se hubiese limitado a constatar que los escritores que con anterioridad habían considerado como un contrato el acuerdo de los Municipios, creían que el objeto del-contrato eran las condiciones de la unión, cuya eficacia consideraban, por tanto, de naturaleza contractual. Pero, rechazada justamente dicha concepción, su error ha consistido en olvidar la posición que los Municipios asumen recíprocamente después del acuerdo y antes de la unión. Dicha doctrina no ofrece respuesta para ninguna de las dos cuestiones siguientes, que, sin embargo, son de gran importancia: 1.", ¿están los Múnicipios obligados a solicitar del Gobierno la emanación del Decreto de unión una. vez estipulado el acuerdo, en el càso de que dicha solicitud no se incluya materialmente en el mismo?; 2.4, presentadas las solicitudes, ¿puede cada uno de los Municipios, independientemente de los otros y sin su consentimiento, retirarla? La respuesta, que indudablemente ha de ser afirmativa en el primer caso y negativa en el segundo, depende precisamente 
del carácter contractual que es necesario atribuir al acuerdo en cuestión (55).

c) Decíamos que otro supuesto del que la doctrina se ocupa con frecuencia, creyendo descubrir un acto complejo en su constitución, era el de la asociación entre entes públicos (56). Como en los dos apartados anteriores, dado el concepto propuesto de acto complejo, tenemos que discrepar de quienes se expresan en tal sentido, por lo que se nos plantea el problema de determinar su verdadera naturaleza.

Es necesario advertir que la terminología legislativa en este punto es extraordinariamente confusa. Unas veces se habla de Consorcios (57), otras de Mancomunidades (58), otras, en fin, de Agrupaciones forzosas (59). En todo caso, lo que interesa resaltar es que existe la posibilidad de que los Municipios se asocien voluntariamente entre sí, o. con otros entes públicos para èl logro de sus fines, en virtud de un acuerdo, cuya naturaleza nos proponemos descubrir.

El Reglamento de población y demarcación territorial de las Entidades locales, de $\mathbf{1 7}$ de mayo de 1952, tras consagrar en su artículo 53 el principio de que los Municipios podrán formar Mancomunidades para obras, servicios $u$ otros fines de la competencia municipal, establece en el artículo 57 y siguientes el procedimiento a seguir para la constitución de la Mancomuni-

(55) En igual sentido se manifiesta entre nosotros S. Royo-Villanova: Los términos municipales cit., pág. 41.

(56) Cfr. Jellinek: Sistema cit., pág. 226; Borsi: Le funzioni cit., pág. 501; Zaмовікі: Corso di Diritto amminisirativo, III, Milán, 1955, pág. 223.

(57) Así, el R. D. L. 10 de febrero de 1928, y los artículos 37 a 40 del Reglamento de Servicios de las Corporaciones locales, de 17 de junio de 1955.

(58) Así, en el R. D. de 19 de febrero de 1924; los artículos 6-11 dei Estatuto municipal de 8 de marzo de 1924; el articulo 26 del R. D. $\mathbb{L}$. de 9 de febrero de 1925 ; la base $1 .^{\star}$ de la Ley de julio de 1934 ; el artículo 1 del D. 14 junio de 1935 ; los artículos 29 y ss. de la Ley de Régimen local, y los artículos 53 y ss. del Reglamento de población y demarcación territorial de las Entidades locales, de $\mathbf{1 7}$ de mayo de 1952.

(59) Así los artículos 38 y 39 de la Ley de Régimen local, y los artículos $65 \mathrm{y}$ ss. del Reglamento de molación y demarcación territorial de las Futidades locales. 
dad. El acuerdo de constitución habrá de ser adoptado en cada Ayuntamiento con el "quorum", señalado en el artículo 103 de 1a Ley; cada uno de los Ayuntamientos interesados designará un representante en la Comisión que haya de redactar los Estatutos de la Mancomunidad, que habrán de ser ratificados por las Corporaciones respectivas en sesión extraordinaria convocada ail efecto. Dichos Estatutos serán sometidos para su aprobación al Consejo de Ministros por conducto del de la Gobernación, previo dictamen del Consejo de Estado. Estos son los preceptos fundamentales sobre los que debemos efectuar nuestra investigación.

Interesa, ante todo, llamar la atenciớn sobre la circunstáncia de que nos encontramos en aquella que Jellinek, en su fundamental monografía sobre los derechos pủblicos subjetivos, ha 1lamado esfera del status libertatis. El Estado no puede imponer da asociación de Municipios, salvo en los casos que la Ley establece. Que no son los que aquí contemplamos. Continuando el examen de las normas consignadas, creemos que se pueden distinguir dos momentos fundamentales en el procedimiento para constituir una Mancomunidad. E1 primero, silenciado por la Ley, es aquel en que un Municipio invita a otros u otros a constituirla. El segundo, el envío para su aprobación de los Estatutos de $\|_{a}$ Mancomunidad y de las Ordenanzas de su régimen a la autoridad central correspondiente. Después del primer momento ha desaparecido el status libertatis de los Municipios, ligados ahora por el cumplimiento de una serie de obligaciones. Así, la de designar a un representante que habrá de participar en la redacción de los Estatutos. Es posible que después ni siquiera se aprueben dichos Estatutos, con lo que la Mancomunidad no llegará a constituirse. Pero aquel primer momento habrá producido todos sus efectos. ¿Qué ha sucedido? La semejanza entre el caso que ahora nos ocupa y el de la unión de Municipios no son, ni mucho menos, insignificantes. Hasta el punto de que nos permiten afirmar que existe también aquí un contrato bi o plurilateral, según el número de Municipios interesados, con el que estos se comprometen a adoptar las medidas encaminadas a la 
constitución de la Mancomunidad, que aparecen reguladas por $\mathbf{r}_{j}$ la Ley.

En este sentido puede interpretarse la Sentencia de 18 de marzo de 1936, en la que nuestro Tribunal Supremo'declaró que es evidente la nulidad del acuerdo que por sí solo adoptó uno de los Ayuntamientos (agrupados a los efectos de la prestación de sus servicios por un solo Secretario municipal), destituyendo al Secretario de la Agrupación que tenía formada con el otro "porque esa Agrupación, voluntaria en su origen, puesto que no fué impuesta por la Administración central, sino que obedeció a un pacto de mutua conveniencia entre los Ayuntamientos, siguió todos los trámites necesarios para adquirir plena validez y eficacia, y, además de las obligaciones que cada uno de los Municipios contrajo con el pacto, y que por ello tenian que cumplir con toda escrupulosidad, al someter la Agrupación concertada a la aprobación del Ministerio y obtenerla, quedaron ligados al cumplimiento de las abligaciones legales establecidas para que las Agrupaciones y Mancomunidades puedan disolversen.

No hemos hablado de aquel que hemos llamado segundo momento fundamental, que se descubre en las normas que regulan la constitución de la Mancomunidad. Es decir, aquel en que sè pide la aprobación de los Estatutos. Tampoco nos hemos referido con anterioridad al acto en que los Municipios piden al Estado que decrete su unión. No ha sido este un hecho casual. Y. ello porque creemos que también en este supuesto nos encontramos ante una misma figura juridica. A la relación contractual que se establece entre los Municipios que tienen por objeto la obligación de pedir en determinadas condiciones su unión o asociación en Mancomunidad, sigue la instancia que dirigen a la autoridad gubernativa. En esta instancia, que evidentemente no es un contrato, sino un acto con el que se ejecuta to que con anterioridad se habia pactado, pueden unirse (pues también será factible que se presente por separado) las voluntades de los Municipios, encaminadas a la producción de un mismo efecto, pero cada una en el propio interés. Por esta razón tampoco, en este caso, podrá hablarse de acto complejo. 
4. Interesa ahora distinguir la categoría del acto complejo de otras figuras afines, que pueden encontrarse en nuestro Derecho positivo. Principalmente, del acto colectivo y del acto colegial (60).

a) Por acto colectivo se entiende, según la doctrina predominante, aquel en que se unen varias voluntades de idéntico contenido, aun permaneciendo distintas, para producir un mismo efecto, con miras a la satisfacción del interés propio.: Es aqui donde se encuentra la diferencia fundamental con el acto complejo. No existe un interés único, sino distintos intereses. La Ley no exige que para la producción de un efecto concurran las dos o más voluntades. Estas se unen, peŕo podrían haber allcanzado su objeto manifestándose aisladamiente. Como apunta Ranelletti, en esta especie de actos existe una sola declaración de voluntad, pero una sola volluntad. La voluntad declarada es sólo la unión de las voluntades declaradas por cada uno de los participantes en el acto (61). De aquí, una importantísima consecuencia: si en el caso de acto colectivo una de las voluntades éstá viciada, el vicio no afecta la validez del acto en cuanto a las demás voluntades se refiere. Lo que, como se sabe, no podría darse si se tratase de acto complejo.

(b) Diverso del acto complejo y del acto colectivo es el acto colegial. Su especialidad consiste en que emana de un órgano colegial. La voluntad administrativa es única, como adviertë Garrido Falla, pero está integrada por distintas voluntades físicas (62). Se trata, por tanto, de un acto simpile. Desde este punto de vista, señala Miele, no es equivocado decir que la voluntad colegial sólo difiere de la voluntad simple -por más que tenga este carácter el acto que en ambos casos se emane- en que la formación de la primera sé opera pón la fusión de varias voluntades de igual contenido que se

(60) Cfr. Lessona: Introduzione al Diritto amministrativo e suoi principi, Florencia, 1952, pág. 76; ForTI: Leaioni cit., II, págs. 97 y 98.

(61) Teoria degli atti amministrativi speciali, Milán, 1945, pág. 120.

(62) Régimen cit., pág. 173. 
dirigen a un mismo fin, mientras que la segunda, se produce en el interior de una persona física. Pero así como en la voluntad simple la actividad interna del sujeto tiene como objetivo la formación de da voluntad, en el colegio el mecanismo de la votación se encamina a constituir una voluntad de la que aquel tiene necesidad para el cumplimiento de sus funciones. La voluntad del colegio, continúa el mismo autor, es sólo la de la mayoria, que por disposición de la ley se erige en voluntad de aquél (63).

Debemos, por esta razón, estimar, de acuerdo con Caserta, que el vicio de la voluntad de los miembros del colegio (por ejemplo, el de la voluntad de un concejal ên un acuerdo del Ayuntamiento pleno) podrá tener relevancia juridica únicamente en el supuesto de que altere la mayoría, mientras que en los demás casos pierde completamente su individuali$\operatorname{dad}(64)$.

\section{Rafael, Entrena Cuesta}

Doctor por la Universidad de Bolonia. Ayudante de Clases Prácticas de la Universidad de Madrid.

(63) La manifesiasione di volontà del privato nel Diritto ammiñistrativo, Roma. 1931, pág. 7, en nota.

(64) Accordo e contratto cit., pág. 235. Este autor llama al acto colectivo, es: ia terminología que nosotros seguimos, acto concursal, y al colegial, acto colectivo. 